\title{
Computer Control System for Reheating Furnace*
}

A computer control systems of reheating furnace is newly developed. To maintain the best product quality, the average level and the uniformity of the billet temperature at the discharging point must be kept in a sufficiently narrow range of allowance. For energy saving, the reheating furnace must be operated to minimize the energy consumption.

The models of gaseous environment of a furnace and the heat conduction on a traveling billet in the furnace are developed. Mathematical programing technique for these non-linear dynamical models is also developed to achieve an optimal heating operation of the furnace.

The control system comprises four models :

\section{Billet Optimum Temperature Profile}

The optimum temperature profile is calculated inreal time to minimize fuel consumption.

Linear programing is used to satisfy both billet temperature level and temperature uniformity requirements. An example of simulation result by linear programing for optimization of fuel flow is shown in Fig. 1. The solid line is the result of manual operation and the dotted line is the result of optimization by this algorithm.

The fuel consumption is reduced in both preheating and soaking zone, while the fuel flow in heating zone is improved compared with the manual operations. The total of fuel flow is reduced about $10 \%$ while retaining the level and uniformity of temperature.

2. Prediction of Furnace Temperature and Billet Temperature

The furnace temperature model, based on a heat-balance equation and volumetric rule of combustion gas, can accurately predict the temperature distribution in the furnace.

The temperature of billets at various points in the furnace is predicted by use of a difference equation.

\section{Furnace Temperature Setup}

The temperatures to be set up at the points in each control zone are determined as a weighted average of the optimum billet temperature profile.

The performance of billet discharging temperature is recorded in Fig. 2. The fluctuation of discharging temperature is controlled satisfactorily within an aimed tem- perature range, most by near to the lower limit.

The application to a plant in commercial operation has proved the effectiveness of the system: at least $10 \%$ of energy saving from the manual operation and the temperature accuracy within $\pm 15^{\circ} \mathrm{C}$ at the extraction of the furnace.

The newly developed control system can be applied to other types of reheating furnace in hot strip and plate mills. The present system is expected to work successfully in the transient state of starting up and accidental stop.

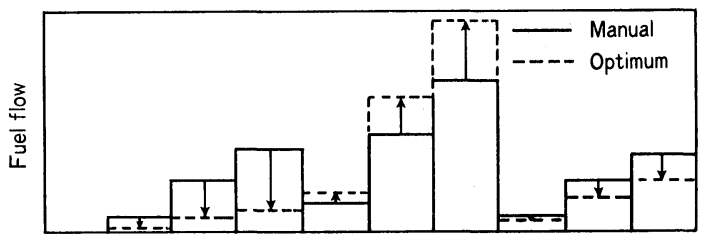

Fig. 1.

Optimized fuel flow and billet temperature in reheating furnace.
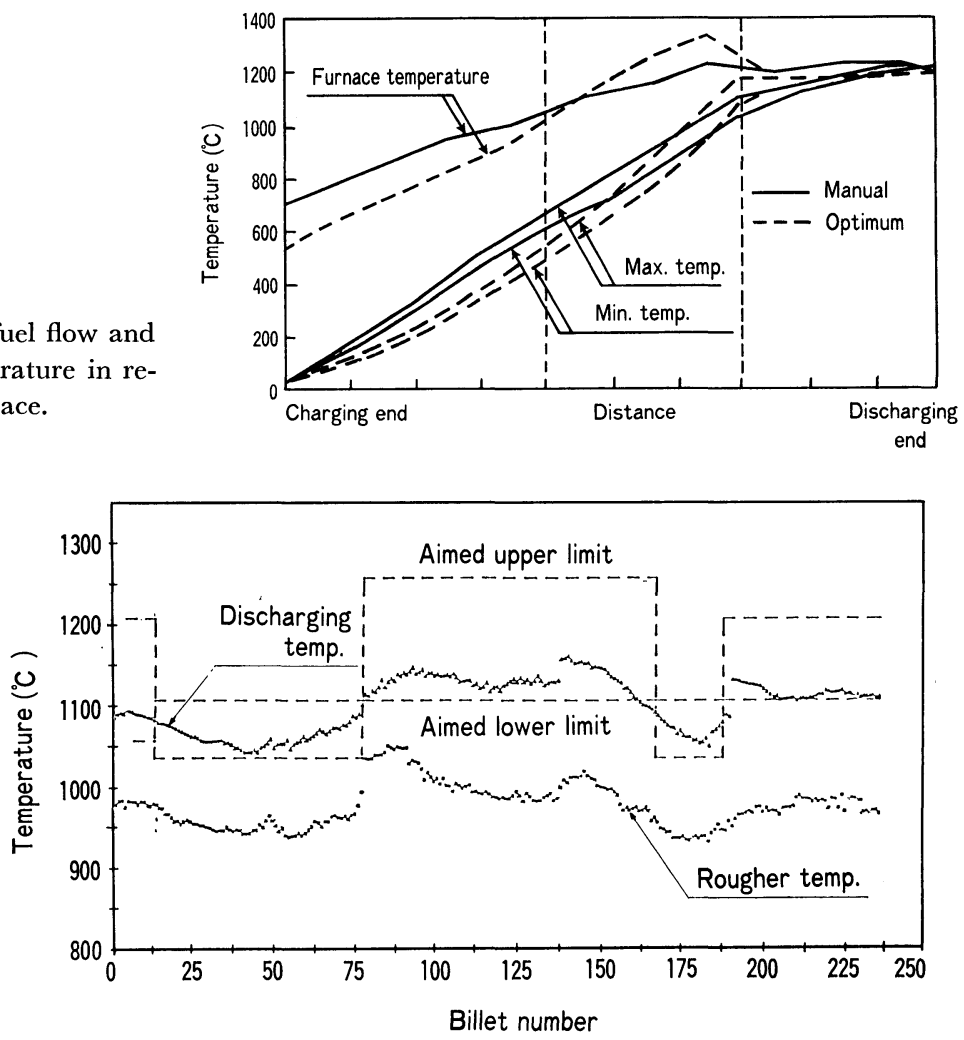

Fig. 2. Temperature control of billet at the discharge of reheating furnace.

* For further information, write to Industrial Projects and Systems Department, Power and Industrial Systems Center, Mitsubishi Electric Corporation, 1-1-2, Wadasaki, Hyogo-ku, Kobe 652. (C) 1987 ISIJ 